Res Publica. Revista de Historia de las Ideas Políticas ISSN: 1576-4184

\title{
Una recuperación necesaria
}

\section{A propósito de Ángel Serafín Porto Ucha y Raquel Vázquez Ramil, María de Maeztu. Una antología de textos, Madrid, Dykinson, 2015, $311 \mathrm{pp}$.}

María Curros Ferro*

Nos encontramos en un momento crucial en que el somos muchas y muchos las que intentamos recuperar la memoria histórica de las mujeres intelectuales que nos precedieron. Este hecho quizá se deba, fundamentalmente, a que somos muy conscientes de que en pleno siglo XXI tenemos un deber con la historia, puesto que el estudio de la humanidad está incompleto y ha sido sesgado. Se trata de mujeres desconocidas que, en general, no han sido reivindicadas a pesar de que cambiaron el rumbo de sus propias vidas y de las de sus congéneres. Por ello, en los últimos años numerosos estudiosos pretendemos, perseguimos y buscamos la recuperación de figuras femeninas que marcaron las décadas precedentes y, fruto de ello, están saliendo a la luz diversos trabajos tan indispensables como interesantes; me refiero -entre otros- a Las Sinsombrero, sin ellas la historia no está completa de Tània Balló ${ }^{1}$ y a su proyecto crossmedia ${ }^{2}$. En el libro indicado (que ha agotado varias ediciones, pese a haber sido publicado por primera vez en febrero de 2016) se aborda la trayectoria de diez mujeres de la Generación del 27: Margarita Manso, Marga Gil Roësset, Concha Méndez, Maruja Mallo, Ángeles Santos, María Zambrano, María Teresa León, Rosa Chacel, Ernestina de Champourcín y Josefina de la Torre. Todas ellas se nos presentan como relevantes, aunque injustamente minusvaloradas. No obstante, no hay un capítulo completo dedicado a María de Maeztu en Las Sinsombrero (si bien aparece citada en el apartado dedicado al Lyceum Club Femenino). Yo considero, sin embargo, que se trata de una de las mujeres más influyentes y notables de la Generación del 14 y, dado que su polifacetismo debe ser conocido y reconocido, voy a centrarme en este trabajo en la figura de la pedagoga vasca María de Maeztu, a partir de la biografía y la antología que nos ofrecen Porto Ucha y Vázquez Ramil en María de Maeztu. Una antología de textos ${ }^{3}$.

El libro editado por Porto Ucha y Vázquez Ramil tiene como aspecto particularmente novedoso el que esté centrado, fundamentalmente, en la obra escrita de María

\footnotetext{
Universidad Complutense de Madrid mcurros@ucm.es

T. Balló, Las Sinsombrero. Sin ellas, la historia no está completa, Barcelona, Espasa, 2016.

2 Dicho proyecto consiste en un documental de televisión (disponible en la página: http://www.rtve.es/lassinsombrero/es), una webdoc, una campaña en redes sociales, un proyecto educativo, etc.

3 Á. S. Porto Ucha y R. Vázquez Ramil, María de Maeztu. Una antología de textos, Madrid, Dykinson, 2015.
} 
de Maeztu. Así, a diferencia de muchos otros textos dedicados al estudio de la pedagoga vitoriana, no se limita a desglosar datos biográficos, analizar las instituciones creadas y lideradas por ella, etc., sino que tiene como fin principal divulgar lo que podemos calificar como el pensamiento pedagógico y filosófico de la autora. Como veremos en seguida, el texto incluye las referencias biográficas oportunas, pero es el punto indicado el que realmente ha de merecer mayor atención por parte de los investigadores y las investigadoras.

María de Maeztu. Una antología de textos puede dividirse en dos partes claramente diferenciadas. La primera de ellas consiste en una puesta en contexto y una biografía de María de Maeztu; la segunda es una antología de textos de la propia pedagoga. En las páginas siguientes trataré de mostrar los puntos fuertes y las características de ambos polos de la obra. Sin embargo, debo señalar desde el comienzo que la selección de textos ha tenido lugar para conmemorar el centenario de la Residencia de Señoritas, $\mathrm{y}$ ha supuesto un intento por unir y ofrecer al público una pequeña selección de artículos y conferencias agrupados temática y cronológicamente. No se trata, pues, de textos encontrados en archivos perdidos y que se ofrezcan con afán de novedad: sólo se pretende su difusión ${ }^{4}$.

La primera parte, formalmente llamada "Estudio introductorio. María de Maeztu, fundamentos y fases de su pensamiento social y pedagógico", tiene dos objetivos prioritarios: ofrecer una visión sinóptica del contexto en el que se desenvolvió la vida de la protagonista de la obra y proporcionar una pequeña biografía de la misma. Ciertamente, la estructura de esta primera parte puede ser ligeramente oscura en tanto en cuanto no aparece ordenada de una manera cronológica: queriendo mostrar que tanto la Residencia de Señoritas como el Instituto-Escuela son producto de la labor de la Institución Libre de Enseñanza (ILE) y de la Junta para la Ampliación de Estudios (JAE), dichos organismos aparecen analizados antes que la biografía de Maeztu, pese a que ésta fue la principal promotora tanto de la Residencia de Señoritas como del Instituto-Escuela.

No obstante la crítica anterior, resulta muy adecuada la filiación que los autores establecen entre el krausismo, la ILE y la JAE, por una parte, y la obra social y pedagógica de María de Maeztu ${ }^{5}$, cuya poca presencia en otros estudios resulta cuanto menos llamativo ${ }^{6}$. La importancia de dichas instituciones en la formación de María de Maeztu resulta palmaria si atendemos, por ejemplo, al hecho de que la JAE concedió al menos dos becas a la autora para estudiar en Londres y en Alemania (donde trabajó con Natorp y Cohen, al igual que hicieron su hermano Ramiro y Ortega y Gasset, los cuales la animaron a emprender la aventura germana). Por supuesto,

Los propios editores lo destacan. Así, inciden en la idea de que los textos de María de Maeztu están diseminados por el mundo, sin estar agrupados en bibliotecas (ibidem, pp. 12-13).

En este punto los autores continúan, acertadamente, la senda ortodoxa a propósito de los estudios sobre la obra de la pedagoga vitoriana. Otros ejemplos en esta línea serían: C. Zulueta y A. Moreno, Ni convento ni college. La Residencia de Señoritas, Madrid, CSIC/Asociación de Amigos de la Residencia de Estudiantes, 1993; o M. Márquez Padorno, "The Eigth Sister. La relación del International Institute y la Junta para Ampliación de Estudios en el avance de la coeducación universitaria en España", en J. Cuesta, M. J. Turrión y R. M. Merino (eds.), La Residencia de Señoritas y otras redes culturales femeninas, Salamanca, Universidad de Salamanca y Fundación José Ortega y Gasset-Gregorio Marañón, 2015, pp. 117-129. Por supuesto, María de Maeztu no es el único caso en que tenga aplicación la influencia de estas instituciones; véanse por ejemplo los libros de Luis Palacios Bañuelos a propósito de José Castillejo, que fuera entre otros cargos secretario de la JAE.

6 Por ceñirme a una monografía reciente, véase M. J. Lastagaray Rosales, María de Maeztu Whitney. Una vida entre la pedagogía y el feminismo, Madrid, La Ergástula, 2015. 
Porto Ucha y Vázquez Ramil no sólo se refieren a la ILE y la JAE: apelan también al International Institute for Girls in Spain, la Residencia de Estudiantes, el Museo Pedagógico Nacional; y a personas concretas, como Fernando de Castro.

Si nos centramos propiamente en el aspecto biográfico de la obra, lo primero que hay que decir es que no deja de lado ningún punto importante. Por supuesto, dada la finalidad del libro, se trata de una biografía breve; aun así, es notorio que en la síntesis ofrecida aparezcan todos los elementos centrales de una vida que, a día de hoy, sigue sin estar del todo clara. A propósito de este último punto, resulta llamativo que ni siquiera haya pleno acuerdo sobre la fecha de nacimiento de María de Maeztu: algunas monografías sitúan la fecha el 18 de julio de $1882^{7}$, algo que también se desprende de su expediente de la Universidad Central ${ }^{8}$; sin embargo, tanto Isabel Pérez-Villanueva Tovar ${ }^{9}$ como Concha D'olhaberriague ${ }^{10}$ sitúan la fecha un año antes, en 1881, al igual que ocurre en el texto que estamos analizando ${ }^{11}$. La controversia, a mi modo de ver, se resuelve del modo en que lo advirtió Pérez-Villanueva y que recogen Porto Ucha y Vázquez Ramil: el hecho de que los padres de María de Maeztu no estuvieran casados, y el de que su padre estuviera en Cuba en el momento de su nacimiento, llevó a que el reconocimiento de la paternidad fuese postergado hasta 1882.

Dado que la importancia y el ocultamiento histórico del personaje lo requieren, creo que es oportuno llevar a cabo una pequeña semblanza de María de Maeztu (Vitoria, 1881- Mar del Plata, Argentina, 1948) la gran desconocida de la Generación del 14 (a cuyo miembro más conocido y maestro de la autora ya nos hemos referido: Ortega y Gasset). Desde muy joven se advierte en ella su vocación por la docencia -quizá influenciada por la profesión de su madre, Jane Whitney, quien dirigía un colegio femenino fundado por ella misma, la Academia Anglo-Francesa, situado en Bilbao (ciudad a la que se había trasladado la familia Maeztu desde Vitoria tras la muerte del patriarca Manuel de Maeztu en Santa Clara, Cuba ${ }^{12}$ )-.

El primer puesto de trabajo que María de Maeztu desempeñará será el de maestra, habiendo finalizado en su ciudad natal los estudios de Magisterio el Año del Desastre ${ }^{13}$, que tanto marcará a la generación de su hermano Ramiro. Poco tiempo después, en 1902, y tras aprobar una oposición, María es oficialmente maestra aunque en este momento no llega a ejercer en el destino que le había sido otorgado, Santander. Posteriormente presentó una solicitud para trasladarse a Bilbao, donde pudo finalmente ejercer desde que toma posesión el 22 de noviembre de $1902 \mathrm{y}$, a la vez, colaborar cuando sea necesario y su tiempo se lo permita con el Colegio de Señoritas Whitney de Maeztu, dirigido por su madre. Ya entonces nuestra protagonista aplicaba entusiasmada métodos pedagógicos modernos por cuya labor llegó a recibir

Cf. A. Rodrigo, Mujeres olvidadas. Las grandes silenciadas de la Segunda República, Madrid, La Esfera de los Libros, 2013, p. 200.

En dicho expediente se puede leer que el 7 de mayo de 1912 tenía 29 años.

Cf. I. Pérez-Villanueva Tovar, María de Maeztu. Una mujer en el reformismo educativo español, Madrid, UNED, 1989, pp. 138-139.

10 Cf. C. D'Olhaberriague, Vida de María de Maeztu, Madrid, EILA Editores, 2013, p. 34.

11 Cf. Á. S. Porto Ucha y R. Vázquez Ramil, op. cit., p. 43.

12 Ibidem, p. 44.

13 En la época que estamos abordando no era necesario tener estudios de bachillerato para acceder a los estudios de Magisterio. Con el decreto del 29 de septiembre de 1931 y la llegada de la Segunda República cambia esta situación. Años más tarde dicho decreto se deroga volviéndose a la etapa anterior, la vivida por nuestra protagonista. Cf. C. D’olhaberriague, Vida de María de Maeztu, op. cit., p. 45. 
varios premios en $1905^{14}$. Mientras tanto, compagina dichos puestos de trabajo con los estudios de bachillerato que finalizará en 1907, tras lo cual se matricula en la Universidad de Salamanca como alumna no oficial para estudiar Filosofía y Letras, si bien años después terminará la titulación en la Universidad Central de Madrid.

En 1908 había comenzado su andadura con la Junta para Ampliación de Estudios "formando parte de la comisión enviada por el Gobierno español para estudiar la sección pedagógica de la Exposición Franco-británica celebrada en Londres"15. Fruto de dicho viaje académico, María de Maeztu redactará el 23 de enero de 1909 el que probablemente sea su primer escrito, "La pedagogía en Londres y las escuelas de párvulos", que a modo de memoria podemos encontrar tanto en el primer tomo de los Anales de la Junta para Ampliación de Estudios como en la Antología de Textos que recoge la obra de Porto Ucha y Vázquez Ramil ${ }^{16}$. En dicho artículo María retrata sus impresiones: Manchester, la escuela de Peterbourog, el Board School o el Froebel Institute, que causan en ella un fuerte impacto, pues el progreso en Inglaterra era más que evidente. No debemos olvidar que nuestra protagonista hablaba varios idiomas, entre ellos el español, el inglés y el francés que había aprendido de su madre Jane Whitney, profesora de idiomas y mujer culta nacida en Niza (por aquel entonces Italia) pero criada en París.

Tras su viaje a Londres, una vez trasladada a la capital de España, María de Maeztu retomará su formación en Filosofía y Letras, titulación que, como ha quedado señalado con anterioridad, había comenzado en Salamanca. Además de ello, desde 1909 asiste a la Escuela de Estudios Superiores del Magisterio de Madrid: al igual que otros alumnos del resto de la Península Ibérica se había desplazado a la capital de España para cursar los estudios correspondientes a lo que ella denominaba el doctorado de Pedagogía ${ }^{17}$, lo que le permitió, por ejemplo, presenciar en octubre de 1909 la primera clase de Ortega y Gasset. Lo dicho nos lleva a pensar que Bilbao y su puesto de maestra en el Barrio de las Cortes se le iban quedando pequeños.

En el curso 1912-1913 viaja a Alemania por primera vez para perfeccionar su alemán con una segunda beca de la Junta para Ampliación de Estudios. Su interés por la didáctica, la pedagogía y la instrucción la embarcan en este nuevo proyecto. Al igual que otros miembros de la Generación del 98 y de la de 1914, María de Maeztu considera que para mejorar la situación de la escuela española hay que beber de los métodos de Europa (aplicaba la máxima de Ortega y Gasset de que "España es el problema y Europa la solución": la autora es muy consciente del atraso de su país con respecto al de países vecinos; por eso, en ninguno de sus proyectos abandona la idea de europeizar España). Por consiguiente, sus estudios en la Universidad de Marburgo (la más antigua de las Universidades Protestantes del mundo) le serán de gran ayuda. En el país teutón, doña María aprovechará no sólo para mejorar el idioma, sino también para visitar diversos centros escolares y para aprender de los más punteros pensadores y pedagogos germanos del momento. Entre éstos, uno de los que más huella dejará en nuestra autora es Paul Natorp, que será traducido años más tarde por la propia Maeztu. Dada su extensa formación no es de extrañar que a María

\footnotetext{
Ibidem, p. 42.

Cf. Á. S. Porto Ucha y R. Vázquez Ramil, op. cit., p. 52.

Ibidem, pp. 110-134.

Cf. M. Maeztu, Antología-Siglo XX. Prosistas Españoles. Semblanzas y comentarios. Madrid, Espasa-Calpe, 1969, 7 a edición, p. 77.
} 
le propongan en 1915 dirigir la que acabará siendo su gran Obra -así denominada por ella misma-: la Residencia de Señoritas de Madrid ${ }^{18}$. Este centro es el equivalente femenino de la Residencia de Estudiantes que había sido creado en el Madrid de 1910 por la Junta para Ampliación de Estudios y que es especialmente conocida por ser la casa de Dalí o Lorca.

El libro de Porto Ucha y Vázquez Ramil resulta, a mi juicio, un tanto escaso en diversos aspectos, siendo particularmente importante su análisis del núcleo fundamental del trabajo que María de Maeztu llevó a cabo durante más de veinte años: la Residencia de Señoritas ${ }^{19}$. La creación de una residencia para mujeres era la tabla de salvación que María de Maeztu propuso para la mejora en la educación de las mujeres, ya que sus congéneres no estaban ni de lejos teniendo las mismas oportunidades que los varones. Con el trabajo de María de Maeztu y con su Residencia se pudo garantizar la igualdad de derechos para hombres y mujeres en ambos centros dirigidos por diferentes intelectuales.

Es bien conocido el dato de que Alberto Jiménez Fraud se encargaba de la masculina; tampoco es ignorada su laxitud extrema, algo que manifiestan los casos de Lorca o Dalí. Sin embargo, las cosas eran completamente diferentes en el caso de la Residencia femenina. Al igual que lo habían hecho los institucionistas de finales del XIX, la cuarta de los Maeztu apostó por la educación... pero no a cualquier precio. En esta Residencia, que admitía mujeres mayores de dieciséis años que viajaban a Madrid para estudiar o no en la Universidad, no se permitía suspender: aquella alumna que no rindiese académicamente era expulsada del centro (tal hecho valió a nuestra protagonista el apodo de María "la Brava" por parte de sus pupilas).

María de Maeztu creía en la igualdad, que aplicaba tanto a su vida privada como a su vida pública. Por ello, la constitución del proyecto femenino de la Residencia de Señoritas era clave. El objetivo que se propuso ya se ha citado con anterioridad: asegurar e igualar la educación y las oportunidades de las mujeres de la misma manera que se hacía con los hombres, máxime cuando ella misma no había dispuesto de un lugar digno donde alojarse y estudiar en su estancia de estudios madrileña ${ }^{20}$. Para colmo, la pedagoga vitoriana había sufrido injustos desprecios al viajar a Salamanca para examinarse en la Universidad y sabía de lo que hablaba. Así lo relata ella misma: "Recuerdo que la primera vez que fui a examinarme desde Bilbao coincidí en el tren con los estudiantes de Deusto. Los muchachos me miraban como a un bicho raro, $\mathrm{y}$ en todo el viaje no dejaron de hacer comentarios, bastante desfavorables para

18 "Los inicios de María como directora fueron complicados, pues había que comenzar de la nada. Contaba, sí, con los edificios, y existía el modelo de la Residencia de Estudiantes, pero se destinaba a varones y universitarios; la empresa de María era arriesgada, aunque en la Junta tenían plena confianza en su viabilidad" (Á. S. Porto Ucha y R. Vázquez Ramil, op. cit., p. 61).

19 Aunque poco a poco van apareciendo estudios sobre este centro, aún queda mucho por hacer. Me parece que es particularmente útil Mujeres en vanguardia: la Residencia de Señoritas en su centenario (1915-1936), Madrid, Publicaciones de la Residencia de Estudiantes, 2015. Esta obra es el catálogo de la exposición que tuvo lugar a propósito del centenario de la institución, e incluye artículos verdaderamente útiles de especialistas, imágenes, obras, documentos, etc.

20 Dice la propia María de Maeztu: "Me alojaba en una casa de huéspedes de la calle de Carretas, donde pagaba un duro. Pero allí no había manera de estudiar. Voces, riñas, chinches, discusiones y un sinfín de ruidos de la calle me impedían dedicarme al trabajo. Comprendía que no habría muchacha de provincias que se decidiera a estudiar en la Universidad a costa de aquello y se me ocurrió que a las futuras intelectuales había que proporcionarles un hogar limpio, cómodo, cordial" (I. Pérez-Villanueva Tovar, María de Maeztu, op. cit., pp. 86-87). 
mí. El hecho de que una mujer joven viajase sola era considerado casi tan reprobable como el que estudiase una carrera" 21 .

La segunda parte de María de Maeztu. Una antología de textos consiste, precisamente, en una antología de textos de nuestra intelectual. Los autores ofrecen los artículos ordenados bajo las siguientes etiquetas: "Etapa inicial"; "Pensamiento pedagógico"; "Feminismo, educación y trabajo de la mujer"; "Obra de divulgación en América" y "Entrevistas". Hay que señalar que, a mi juicio, dicha categorización de los artículos ha de considerarse de manera flexible. Con ello quiero decir que algunos artículos podrían haber mutado su lugar en la obra: "La pedagogía en Londres y las Escuelas de Párvulos", de 1909, aparece incluido en la "Etapa inicial", aunque bien podría haberse subsumido en la categoría "Pensamiento pedagógico" en tanto en cuanto es un análisis de las escuelas inglesas: su funcionamiento, organización, etc. Otro ejemplo: en la sección "Obra de divulgación en América" encontramos textos cruciales como "Concepción Arenal", de 1926, el cual ciertamente fue leído como conferencia en el Club Español y apareció publicado en Buenos Aires... aunque con anterioridad había sido dictado en Salamanca. No pretendo con todo esto criticar la ordenación llevada a cabo por los editores, sino señalar que no ha de hacerse una lectura rígida de la misma.

No puedo detenerme en un pormenorizado análisis de los textos que ofrece esta antología, y tampoco tengo derecho a privar al lector de descubrirlos por sí mismo. Sí me gustaría, sin embargo, hacer especial hincapié en los que considero son los dos temas fundamentales de cuantos se abordan en los distintos artículos y conferencias: la pedagogía y el feminismo ${ }^{22}$. En este sentido, es sumamente relevante "Desde Alemania. Pestalozzi y su idea del hombre", de 1913, en la medida en que pone de manifiesto la importancia capital que el pedagogo suizo tiene en el pensamiento de Maeztu; y también considero fundamental "The Higher Education of Women in Spain" y "Lo único que pedimos". El primero de ellos nos ofrece un panorama de la situación de la mujer en la universidad española ${ }^{23}$, mientras que el segundo - de tono más ensayístico- supone toda una reivindicación de la igualdad de los derechos de la mujer, quizá la mejor de las escritas por María, que puede condensarse en la decisiva frase con que se inaugura: "Soy feminista: me avergonzaría de no serlo"24.

Quiero cerrar esta nota destacando el esmero de los editores a la hora de elaborar tanto la bibliografía como el índice onomástico. Además, sería injusto no reconocer el mérito y la valía de las numerosas notas al pie, fantásticamente documentadas, que permiten no sólo poner ante el lector un panorama general de la época y el contexto de los escritos, sino también hacer de éstos algo plenamente inteligible y aclarador. A ello añaden una serie de fotografías notoriamente acertadas. Más

Cf. la entrevista realizada por Josefina Carabias a María de Maeztu: "Las mil estudiantes de la Universidad de Madrid", en Estampa, n 285, 24 de junio de 1933.

22 Como he señalado con anterioridad, las etiquetas temáticas proporcionadas por los editores no deben confundirnos: creo que tiene pleno sentido analizar desde el punto de vista de la investigación sobre el feminismo de Maeztu el texto de 1926 "Estado actual de la cultura femenina en España", que aparece en la categoría "Obra de divulgación en América".

23 Resulta muy curioso un dato vital: a partir de este estudio, María de Maeztu pide datos nada menos que a Miguel de Unamuno sobre el número de estudiantes matriculadas en la Universidad salmantina, aprovechando la cercanía que tuvo con el célebre rector (lo hace en una carta enviada desde Madrid el 5 de junio de 1920 (puede leerse en: J. I. Tellechea Idígoras y L. Robles, "Cartas de tres Maeztu a Miguel de Unamuno", en Cuadernos Salmantinos de Filosofia, XVII, 1990, carta n ${ }^{\circ} 10$ ).

24 Á. S. Porto Ucha y R. Vázquez Ramil, op. cit., p. 221. 
allá de las críticas puntuales que me he atrevido a verter, estamos frente a un tomo de notable importancia, excelente edición e interés erudito de cara a recuperar a esa figura extraña que fue María de Maeztu, injustamente conocida (en la mayoría de los casos) por la fama de sus hermanos Ramiro y Gustavo (pintor de renombre) y que debería estar en nuestro agradecimiento a la altura, por ejemplo, de autoras como Clara Campoamor. 